\title{
DESCONSTRUINDO O NAÏF: A PINTURA DE ALCIDES PEREIRA DOS SANTOS $^{1}$
}

DECONSTRUCTING THE NAÏF: THE PAINTING OF ALCIDES PEREIRA DOS SANTOS

Ludmila de Lima Brandão

Doutora em Comunicação e Semiótica pela PUC/SP. Docente do Programa de Pós-Graduação em Estudos de Cultura Contemporânea da UFMT.

Suzana Cristina Souza Guimarães

Doutora em História pela PUC/RS. Docente do Programa de Pós-Graduação em Estudos de Cultura Contemporânea da UFMT.

Programa de Pós-Graduação em Estudos de Cultura Contemporânea Universidade Federal do Mato Grosso (UFMT)

Cuiabá - MT - Brasil

Endereço:

Rua 12, Quadra 16, Casa 05 Jardim Universitário Cuiabá - MT

CEP: 78075.545

E-mails:

ludbran@terra.com.br suzanaguimaraes@rocketmail.com

RESUMO

É lugar-comum na história e na crítica de arte, antes de qualquer análise mais consistente da produção de um artista originário das classes populares, na maioria das vezes, autodidata, classificá-lo como primitivista ou naïf (entre outras designações similares). Temos que essa categorização, longe de ser um indicativo de sua poética ou a que grupo ou movimento se vincularia pelas proximidades temáticas ou estilísticas (como ocorre no circuito oficial da arte), funciona como um indicador social, um signo de procedência. Ao modo do que ocorre com o saber, identificamos nesse procedimento a perpetuação de um dispositivo de colonialidade que, de uma só vez, entroniza a estética ocidental e a arte produzida sob sua chancela como o modelo a ser seguido e desqualifica toda a experiência aesthésica que não se ofereça à conceitualização nos termos ocidentais. Visando desconstruir as categorias, apresentamos o caso singular da obra do artista plástico brasileiro Alcides Pereira dos Santos (Rui Barbosa BA 1932 - São Paulo SP 2001). Em linhas gerais, pode-se dizer que as poucas descrições, opiniões e discursos até agora proferidos sobre ele contribuíram e reforçaram a ideia de que sua pintura é resultado da prática ingênua do que se vê e se olha. Neste caso, ela se prestaria apenas a reproduzir uma realidade. No entanto, ainda que Alcides pareça não recusar o paradigma da representação e a relação entre modelo e cópia que este pressupõe, sua figuração opera uma desconstrução na medida em que os meios de criação tornam-se fins, fazendo com que sua imagem produza um mimetismo que destrói o modelo em vez de preservá-lo.

PALAVRAS-CHAVES: Colonialidade da arte. Naïf. Alcides Pereira dos Santos. 
It is commonplace in art history and criticism, before any more consistent analysis of the production of an artist from the popular classes, often self-taught, to classify the artist as primitivist, or naif (among other similar designations). We understand that this characterization, far from being an indicative of his poetic or the group or movement with which he is associated, by thematic or stylistic proximities (as occurs in the official art circuit), works as a social indicator, a sign of origin. As occurs with knowledge, we identify, in this procedure, the perpetuation of a device of colonialism which, at the same time, imposes the western aesthetic and the art produced under its seal of approval as the model to be followed, and disqualifies all the aesthetic experience that does not lend itself to conceptualization in western terms. Seeking to deconstruct the categories, we present the unique case of the work of Brazilian plastic artist Alcides Pereira dos Santos (Rui Barbosa BA 1932 - São Paulo SP 2001). In general terms, it can be said that the few descriptions, opinions and discourses about him up to now have contributed and reinforced the idea that his painting is the result of a naïve practice of what is seen and observed. In this case, it would serve only to reproduce a reality. However, even if Alcides seems not to refute the paradigm of the representation and the relationship between the model and the copy that it presupposes, its figuration operates a deconstruction in that the means of creation becomes ends, turning the image produced into a mimicry that destroys the model instead of preserving it.

KEYWORDS: Colonialism of art. Naïf. Alcides Pereira dos Santos.

\section{A COLONIALIDADE DA ARTE}

No ensaio "A topologia do Ser e a geopolítica do conhecimento: modernidade, império e colonialidade", Nelson Maldonado-Torres localiza em Heidegger e, curiosamente, em Lévinas - um dos críticos mais virulentos de Heidegger - as origens disso que passa a chamar, na companhia de Charles Bambach, de "racismo epistêmico". Trata-se aqui de um racismo que não é nem biológico, nem cultural, mas que, como essas formas, "descura a capacidade epistêmica de certos grupos de pessoas" tendo, ao fim e ao cabo, o mesmo resultado: "evitar reconhecer os outros como seres inteiramente humanos". Tanto em Heidegger quanto em Lévinas, a busca de raízes que legitimassem a Europa e o Ocidente como o (único) espaço responsável pelas grandes realizações humanas resulta na desqualificação/subalternização de todos os demais não europeus e não ocidentais como incapazes de produzir qualquer coisa de notável, especialmente o pensamento.

A idéia de que as pessoas não conseguem sobreviver sem as conquistas teóricas ou culturais da Europa é um dos mais importantes princípios da modernidade. Há séculos que esta lógica é aplicada ao mundo colonial. (MALDONADO-TORRES, 2008: 77).

Essas são, portanto, as bases da mais longa e entranhada dominação, para além de todas as outras - a dominação epistemológica - , como um dos modos de perpetuação do colonialismo "essa relação extremamente desigual de saber-poder que conduziu à supressão de muitas formas de saber próprias dos povos e nações colonizados, relegando muitos outros saberes para um espaço de subalternidade" (SANTOS, 2009: 7).

$\mathrm{Na}$ atualidade, desde vários lugares, vai se construindo um amplo e diversificado debate, munido por especificidades de pesquisas locais sobre a produção do saber, como as encaminhadas por Boaventura dos Santos (e pesquisadores a ele associados) que exploram a valiosa ideia das "epistemologias do sul" e do "epistemicídio" contra elas perpetrado ou aquelas outras de pesquisadores que, na esteira da obra de Aníbal Quijano, desdobram noções como colonialialidade do poder, do saber, do ser e, mais recentemente, da arte.

No caso especificamente da arte, ou melhor, da estética (entendida como filosofia da arte) e da arte (em tanto que experiência/experimento estético), importantes démarches vem sendo realizadas no âmbito do coletivo modernidad/colonialidad, conhecido também como Proyecto M/C, do qual fazem parte Walter Mignolo e Zulma Palermo, entre outros pesquisadores na América Latina, nos Estados Unidos e na Alemanha. 
Ainda que o pensamento crítico sobre a arte na América Latina não seja de agora, como nos lembra Zulma Palermo (2009) ao citar os estudos sobre o barroco americano, a antropofagia brasileira, as perspectivas da transculturação e dos processos de hibridação que lidam, cada qual a seu modo, com o fato inescapável da diferença colonial, a pesquisadora argentina questiona a suficiência das respostas até então encaminhadas e propõe seguir adiante, explorando diversas questões a exemplo da diferença estabelecida entre arte e artesanato e sua valoração hierarquizada.

Igualmente mencionada por Palermo, interessa-nos nessa hierarquização compreender em que consiste a construção e o uso de categorias como "naïf" e "primitivo" para designar a pintura de artistas de extração popular, na maioria das vezes autodidatas que, longe de ser um indicativo de sua poética, como ocorre quando se trata de artistas do circuito oficial, funciona como um indicador social, um signo de procedência. Para isso, seguiremos a trilha aberta por Walter Mignolo sobre a Estética Ocidental.

No artigo intitulado Aiesthesis Decolonial, Mignolo (2010) nos recorda que a palavra aesthesis, originada do grego antigo, remete a significados como "sensação", "processo de percepção", "sensação visual", sensação gustativa" ou "sensação auditiva". Daí deriva, por exemplo, a palavra synaesthesia, que se refere ao entrecruzamento de sentidos e sensações.

No entanto o que autor nos apresenta em seguida é o fato, da maior importância aqui, da redução da ampla significação do vocábulo à exclusiva "percepção do belo", dando ensejo ao nascimento do termo "estética", a partir do século XVII. Para Mignolo, esta operação cognitiva, que nada tem de ingênua, resulta na colonização da aesthesis pela estética, pois enquanto a primeira é comum a todos os viventes dotados de um sistema nervoso, "la estética es una versión o teoría particular de tales sensaciones relacionadas con la beleza" (2010: 14). Nada teríamos a objetar se esta operação que se deu no século XVIII em solo europeu a ele se restringisse. O problema é que

(...) la experiencia singular del corazón de Europa traslada a una teoría que "descubrió" la verdad de la aesthesis para una comunidad particular (por ejemplo, la etnoclase que hoy conocemos con el nombre de burguesía), que no es universalizable. (MIGNOLO, 2010: 14).

Em resumo, o que aqui se critica é a ambição universalizadora das experiências particulares europeias e a sua disposição hegemônica. Neste caso, a redução da aesthesis - que não mantém nenhuma relação necessária com a beleza - a estética, além de assentar as bases para a construção de sua própria história - a história da estética na Europa -, que se passa por história (da estética) universal - desvaloriza ou, no mínimo, decide ignorar toda experiência aesthésica que não se ofereça à conceitualização nos termos ocidentais.

Pedro Pablo Gomes Moreno, editor da revista Calle 14, em seu número dedicado à questão estética, no editorial dessa edição (2010: 8-9), oferece-nos uma pista ao lembrar o escrúpulo com que Luigi Pareyson (1918-1991) admitiu a existência de uma artisticidade genérica presente em todos os campos de nossas atividades, reconhecendo, enfim, que há arte em toda atividade humana. O eminente filósofo italiano, de modo a evitar que tudo passe a ser caracterizado como arte, propõe a distinção entre o "fazer com arte" de quaisquer obras bem-sucedidas em seu gênero, e o "fazer arte" daquilo que presume e aceita valer só como forma, uma forma que vive de per si (PAREYSON, 2001: 33). Mas, ao contrário de uma perspectiva que disporia a arte e a não arte em lados opostos inconciliáveis - afinal, ele admite a artisticidade humana genérica - , Pareyson propõe que pensemos essa distância em termos de uma passagem gradual de um a outro, como aquilo que "dos primeiros esboços oferecidos por aquele tanto de inventividade que é exigido pela atividade mais regulada e uniforme, alcança as mais altas e desinteressadas realizações da arte" (2001: 33). No exemplo que oferece como corolário da reflexão, na qual situa, em uma extremidade, a "mais ingênua procura de efeito no canto popular (grifo nosso)" e, em outra, "a música mais abstrata" (2001:34), podemos imediatamente ver as consequências da distinção que, ao contrário do sugerido pelo termo passagem, que permitiria uma visualização horizontal do percurso de um ponto a outro, a distinção funda uma verticalidade matizada pela hierarquia.

Não é coincidência a semelhança que guarda com as primeiras teorias antropológicas evolucionistas em que a distância entre o primitivo e o civilizado é medida segundo o grau de "falta" que o primeiro apresenta em relação à completude do segundo: falta escrita, falta ciência, falta estado, falta arte autônoma/verdadeira. 
Do outro lado do Atlântico, interessado que está em reivindicar para os EUA a continuidade da tradição modernista nas artes plásticas, Clement Greenberg (1909-1994), na mesma chave estética da "arte verdadeira", advoga uma lenta evolução que se desenharia desde os impressionistas europeus em direção à abstração e à planaridade que, naquele momento, via se realizar nos Estados Unidos. Tudo o mais, da pop art emergente ao fenômeno kitsch associado aos avanços da industrialização e da classe média, passando por toda a produção popular, era rapidamente excluído da rubrica arte pela doutrina modernista de Greenberg e seus seguidores.

Com Greenberg, a América, especialmente os EUA, não apenas segue na obediência aos cânones europeus como os faz seus, numa evidente operação neocolonizadora que, de modo mais realista que o rei, dissemina o modernismo como um verdadeiro programa de "educação" do olhar/sentir que se espraiará por diversos outros campos além das artes.

Felizmente, apesar da eficiência (neo)colonizadora das mentes e dos sentidos - a ver o que tornaram possível a história e o ensino oficiais da arte que, com raras exceções, tem sido história e ensino da arte europeia/norte-americana recente -, práticas artísticas não Ocidentais e suas aesthesias singulares persistem nos interstícios socioculturais que, de algum modo, escaparam à força dos discursos e práticas hegemônicos.

\section{DESCONSTRUINDO O NAÏF}

Se o kitsch urbano-industrial e os pós-modernismos (que aprenderam muito com o primeiro) representaram o confronto direto com as máximas modernistas, em seus considerados excessos de cor e forma (less is bore), nas combinações espúrias, misturas de gêneros, nos usos dessacralizados da arte e assim por diante, as produções reunidas sob as designações de "naïf" e "primitivo", entre outras $^{2}$, ao contrário de serem imediatamente excluídas da arte como rubrica, foram "acomodadas" no âmbito dessas novas categorias.

Goldstein aponta que, desde o século XX, a noção de arte primitiva constituiu-se "como um guarda-chuva semântico, que engloba manifestações tão distintas como colagens feitas por pacientes psiquiátricos, pinturas pré-históricas e artefatos produzidos por cidadãos ocidentais sem instrução artística" (2008: 303).

Como dissemos anteriormente, "primitivo" ou "naïf", mais do que dizer algo a propósito das obras que reúne, seja por semelhança formal, seja pelas temáticas recorrentes, diz sobre a procedência dos autores dessas obras, ou seja, de sua origem popular, da ausência ou insipiência da formação escolar e artística, de sua suposta "simplicidade", como em geral adjetivam os modos de viver, pensar e ser das pessoas oriundas das classes pobres.

Essa origem de tais artistas, no entanto, não transformou suas produções em ameaças ao discurso hegemônico, ao modo do kitsch e dos pós-modernismos, e o fato de sempre terem sido subestimados foi provavelmente responsável por sua "inclusão" nas margens das artes oficiais. Daí que suas obras passam, em geral, despercebidas, confinadas aos circuitos locais/regionais ou às galerias especializadas que, por sua vez, são marginais em relação às mais bem-sucedidas e dedicadas às obras e artistas de primeiro time.

Goldestein afirma também que tais rótulos produziram pelo menos duas consequências mais diretas: a primeira é centrada na visão eurocêntrica que considera primitivo toda a manifestação artística portadora de valores estranhos ou diversos dos vigentes nas sociedades ocidentais economicamente avançadas; e a segunda de caráter mais genérico, associa tal termo a tudo que é criado pelo povo ou àquilo que lhe é destinado.

Em geral, a história, a antropologia, a sociologia e a crítica de arte, especialmente, convertem as obras desses artistas em objetos a serem sondados pelo que dizem da especificidade de sua condição sociocultural e não pelo que são como proposições estéticas. São pretextos para falar do grupo social e não do fato artístico. Por isso, os estudos acadêmicos e a própria crítica (guardando-se raras exceções) acabam por reafirmar apenas isso que dizem que são - populares - ou, indiretamente, o que não são: artistas do circuito oficial que operam em consonância com a estética, a história e a crítica de arte. Essas designações, ao final, forjam uma espécie de licença para serem chamados de arte - sempre nas margens -, fazendo ainda parecer que se trata de um ato de generosidade. 
Ainda assim, é preciso explicitar as raras locuções que pretendem dizer algo sobre a obra, ou suas características intrínsecas, mas que acabam remetendo ao autor e que são basicamente as mesmas: simplicidade, espontaneidade/intuição e ingenuidade.

É pertinente lembrarmos aqui a curiosa história do artista francês Henri Rousseau (1844-1910), que teria motivado o uso, pela primeira vez, do termo naïf para caracterizar seu trabalho. Ao ousar, em 1885, submeter duas obras ao Salão dos Artistas Independentes, uma vez que haviam sido recusadas pelo Salão dos Artistas Franceses, recebeu uma avalanche de críticas, especialmente irônicas, do meio artístico (inclusive dos emergentes modernos). Dizia-se de suas obras - para fazer notar a inexistência de instrução artística - que elas lembravam garatujas infantis. Tido por alguns como um elogio (ao que parece equivocadamente), é célebre a suposta afirmação de Picasso de que haveria em seu trabalho "uma força gigante escondida em sua simplicidade".

Elogio ou não, o que nos interessa aqui são os termos dos comentários que identificam sua obra como "infantil" e, portanto, ingênua, intuitiva, sem capacidade crítica, e "simples", ou seja, sem a complexidade só atribuída às pessoas com formação acadêmico-científica. Vemos então que o que se deu de Rosseau aos nossos dias foi apenas uma inversão do valor atribuído às supostas características da arte "naïf" ou "primitiva": o que era antes considerado desprezível do ponto de vista estético, passa a ser apreciado pelo que tem de autêntico e puro, insistindo, assim, por nelas reconhecer as mesmas e exclusivas características.

Para não chamar de "infantil" (que em termos atuais resulta pejorativo), os críticos em geral continuam a dizer que essas obras resultam da ingenuidade de seu autor, de sua intuição, e não do trabalho intelectual de quem está na maturidade, que implica pesar suas escolhas formais, em comparar intenções e resultados, que avalia estes últimos e sobre eles interfere indefinidamente ou finaliza. Essa ingenuidade indicaria uma ausência da mediação do pensamento. Ao contrário de pintar com o cérebro, os "naïves" pintariam diretamente com a "alma" e por isso escolheriam temas regionais, lembranças da infância, festas populares. Essas afirmações quase sempre vêm sancionadas por referências a autores como Jung, que defendeu a ideia de uma espécie de alma coletiva para as comunidades tradicionais. A ingenuidade remete ainda à incapacidade crítica em reconhecer o "mau gosto" no uso de formas e cores e mesmo nas escolhas temáticas (como tudo o que se exclui da cartilha moderna) e dele se livrar. Mas por isso mesmo são considerados autênticos.

A "simplicidade", por sua vez, é o adjetivo mais utilizado para supostamente elogiar as pessoas das classes populares. Ao negar a complexidade ou, mais apropriadamente a hipercomplexidade característica das sociedades humanas, a esses indivíduos, ao modo do que é comumente feito com os pertencentes às sociedades indígenas, advoga-se uma proximidade com a natureza, com o "natural" e, por conseguinte, uma maior distância da artificialidade complexa da cultura e da civilização, tornando-os "puros" aos olhos dos ocidentais. Por essas razões, podemos dizer que a produção artística designada de "naïf" está para a arte ocidental do mesmo modo como as sociedades ameríndias estão para o Ocidente.

Diz-se também dos procedimentos artísticos na criação popular que eles seriam avessos ao movimento, à mudança e à multiplicidade e que, por isso, permaneceriam idênticos a si mesmo. É visível a disposição generalizada dessas leituras de encontrar nas obras de tais artistas índices e traços que possam identificá-las com uma singularidade local ou, ainda, compreender seu fazer artístico como a serviço de uma arte crível, marcada por uma suposta postura realista, figurativa e, como tal, representativa de um imaginário primitivista e localista que permitiria aproximar a pintura da experiência vivida pela comunidade a que pertenceria seu autor.

Assim, em tais leituras que naturalizam as categorias "naïf" e primitivo, e com elas se satisfazem, preponderantes até hoje, é impossível ignorar a construção recorrente de um tipo de análise interpretativa que condiciona a produção imagética ao exercício das regras da figuração que (obrigatoriamente) implicavam narrar uma história, representar algo, fazer como. Na gênese desse discurso crítico, o ato de criação aparece normalmente associado a um nome próprio, a um indivíduo real, exterior e anterior que remonta a uma interioridade do pintor. Vista, enfim, como um ato de confissão narcísico, essa pintura é assim associada (e legitimada) à ideia de que, entre esses artistas ainda é possível (e somente isso é possível) trazer um passado, reconstituir uma identidade, abrigar uma autenticidade pessoal. Seriam atos pictóricos capazes de inscrever algo concreto e efetivamente familiar: eles mesmos.

312 Ludmila de Lima Brandão e Suzana Cristina Souza Guimarães - Desconstruindo o Naïf ... 
Simplicidade, espontaneidade/intuição, ingenuidade, imutabilidade e autorreferenciação são alguns dos termos que se perpetuam nessa longa sucessão de equívocos, preconceitos e neocolonialismos veiculados por categorias que mais invisibilizam do que dão a ver, que mais homogeneízam do que dizem suas singularidades.

\section{ALCIDES PEREIRA DOS SANTOS}

No caso de Alcides Pereira dos Santos, suas produções pictóricas também foram tratadas nos termos apontados (ingênuo, simples, infantil, etc.), a despeito de apresentar uma obra de potências múltiplas que não pode ser confinada às instâncias de sua produção, seja em suas imbricações morais, sociais ou regionais. Urge que seja apreciada e estudada pelos valores composicionais, pelos afetos que engendra, os devires que dispara, enfim, pelos seus complexos processos de produção de sentidos e sensações.

Grande parte da produção plástica de Alcides Pereira dos Santos foi desenvolvida a partir do final dos anos setenta do século passado em Cuiabá, Mato Grosso e, posteriormente, a partir do ano dois mil, em São Paulo. Ainda que Alcides, à primeira vista, pareça não recusar o paradigma da representação e a relação entre modelo e cópia que este pressupõe, sua figuração, longe de se ater a algum modelo, opera sua desconstrução, na medida em que os meios de criação tornamse fins, fazendo com que a imagem produzida pelo que seria um mimetismo, destrua o modelo em vez de preservá-lo.

A esse propósito, é preciso lembrar que o ato de ver, por si só, já produz seu paradoxo, sua problemática, uma vez que não existe um real fora da invenção de um sentido, de uma dobra de significações que precede o ser. Por isso, pintar o que se vê não constitui jamais uma cópia do real, mesmo que seja essa, deliberadamente, a intenção. E, antes de tudo, um estar entre, "um permeio sempre renovado que, sendo anterior à divisão entre sujeito e objeto, 'fundamenta tanto o mundo quanto o ver'", como nos esclarece Marcelo Duprat Pereira (2010:47).

Abrindo caminho para outros desdobramentos da imagem de Alcides, diríamos que seu processo criativo encena uma obcecada busca pela excelência e perfeição. Para o filósofo Claudio Ulpiano (1989:1), "quando nós formamos a ideia de perfeição, admitimos que aquilo que é perfeito está contente consigo próprio". Em Alcides, identificamos uma preocupação contínua em compor uma narrativa visual, investindo naquilo que aumentava sua força de existir ou sua potência de agir, como, por exemplo, no que revela seu fascínio pela criação divina (temas bíblicos, riquezas naturais), mas igualmente pela fabricação humana (estradas, fábricas, meios de transportes, lavouras, etc.).

"Minha pintura é criação", dizia o artista (REVISTA CONTATO, 1993:13) e sua obra trata, sobretudo, de edificar o corpóreo. É a alegria e o êxtase com a coisa criada que o move, na medida em que a relação entre trabalho e natureza faz gerar as coisas boas de Deus. É essa força que o rege quando produz, imageticamente, seus outros mundos. A presença da materialidade física, compreendida por um mundo firme, sólido e concreto, já se encontra instaurada na obra, ela é o sensível de sua imagem pictural. 


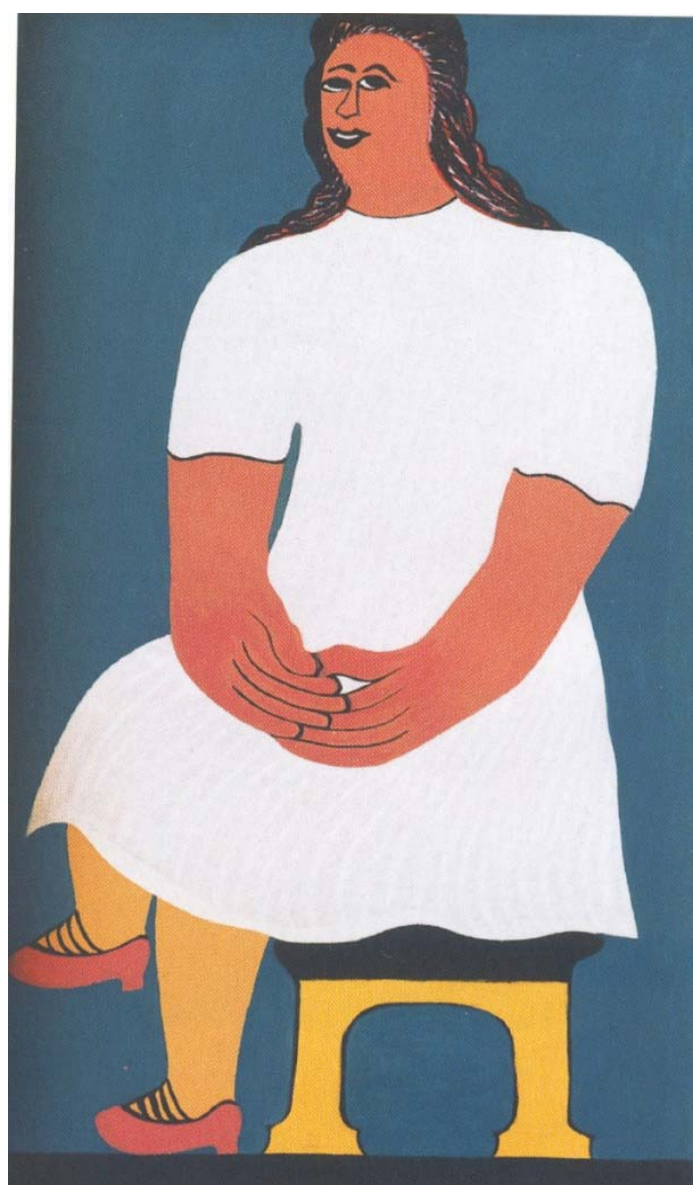

1. Alcides Pereira dos Santos: Retrato de Dalva de Barros, 1988. Óleo sobre tela, 70 x 35 cm. Coleção da artista, Cuiabá, MT.

Os afetos e os perceptos, conforme os concebem Gilles Deleuze e Félix Guattari em O que é a Filosofia?, resultam efetivamente da relação direta com a matéria, com a forma sólida e resistente. E é isso o que se vê/sente em "Retrato de Dalva de Barros" (reprodução 1). Em um plano fechado, a presença absoluta da mulher de formas generosas contraria quaisquer aparências da visão, da mulher que a teria inspirado. Tudo no quadro revela uma atitude exemplar e, curiosamente, a largueza e a robustez do corpo feminino não o tornam vigoroso e austero, mas o seu oposto. Dele emergem suavidade e uma insuperável elegância. O corpo branco, pacificado, tem como contraponto o amarelo vívido das pernas (da mulher e do banco), que convoca o movimento, que transforma a imobilidade em um instante, apenas.

Contra a insistência na representação, no mimetismo como escolha estética, podemos dizer categoricamente que o que Alcides busca não é a semelhança formal com a figura franzina, magra e recatada de sua amiga e mentora, Dalva de Barros com quem conviveu no Ateliê Livre da UFMT, mas perenizar os atravessamentos, as sensações mesmo, experimentadas em sua relação com Dalva.

Pode-se enfim afirmar que as proporções na composição foram ignoradas não por desconhecimento técnico ou inabilidade, e sim porque não eram importantes, ou exatamente porque eram necessárias a "inverossimilhança geométrica, (a) imperfeição física, (a) anomalia orgânica do ponto de vista de um suposto modelo" (DELEUZE; GUATTARI, 1992: 214) para produzir o efeito desejado, os afetos que buscava. A forma desmedida e desproporcional de Alcides é, antes de tudo, um sinal de consistência que mobiliza uma vontade, e ao final, a estrutura aparentemente rude e tosca, resulta no todo, em uma composição de justas medidas: sutil, delicada, expressiva.

Deleuze e Guattari, ao compreenderem as obras de arte como "seres de sensação", aos quais se chega ao trabalho com as matérias e as formas, delas extraindo (ou com elas esculpindo) afetos e perceptos, lembram que os perceptos na obra não são as percepções daqueles que as experimentaram 
e que os afetos que nela identificamos não são os sentimentos. Em ambos os casos, são muito mais do que aquilo que atravessou afetado e percipiente, ou seja, ainda que Alcides tenha partido de sua percepção da amiga (hiperbólica, grandiosa), o que permite que a obra ultrapasse a mera simbolização de seus sentimentos e ganhe existência em si, como "ser de sensação", é o fato de o artista ter conseguido imprimir na matéria algo que excede sua própria experiência, que se eterniza na obra. As forças incorpóreas que encarnam a pintura, todas as vezes nas quais ela é olhada, que conseguiu esculpir diligentemente, ultrapassam as histórias pessoais de Alcides e Dalva, mantémse em pé, como diriam Gilles Deleuze e Félix Guattari (1992:214), sagrando a plena artisticidade da obra como ser de sensação.

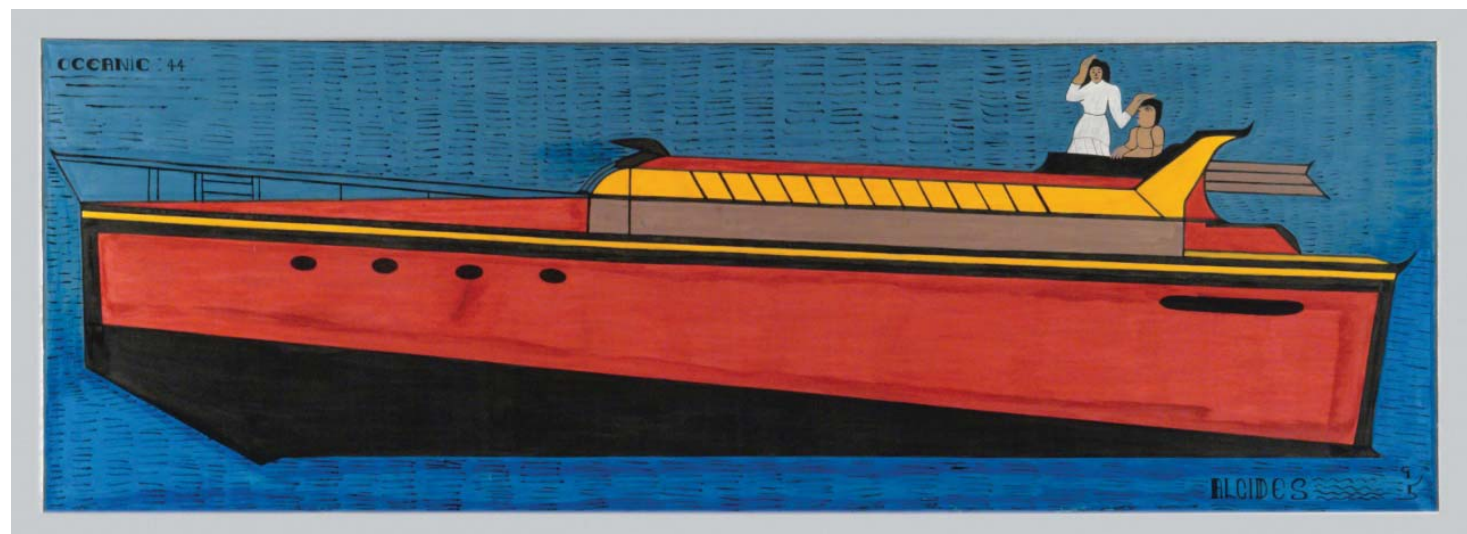

2. Alcides Pereira dos Santos: Oceanic 44, 1995. Óleo sobre tela, 70 x 205 cm. Coleção Vilma Eid, SP.

De outra parte, podemos também compreender a força de uma obra artística pelo devir que engendra e não por aquilo que ela supostamente é ou pretende representar. Devir, ao se definir como aquilo que não é, mas que vem a ser, ou melhor, que está em vias de ser, se materializa como uma linha de fuga, como uma força que nos carrega para outras paragens.

É, certamente, o que ocorre em "Oceanic 44" (reprodução 2). O barco, ou sua espécie de "nau dos insensatos", singra o mar para um lugar ignorado. A diagonal que corta a tela da popa à proa impõe o sentido do movimento para fora do quadro. Os aparentemente pouco importantes detalhes das mãos da mulher (para trás), que repetem as três finalizações pontiagudas (alta, média e baixa) da embarcação formam o contraponto com a direção geral do Oceanic, indicando "o que ficou para trás", mas também reforçando a fuga, o movimento que impele o barco e nos leva consigo.

Sobre essa virtude Paulo Sérgio Duarte diz:

E a pintura de Alcides? Tudo plano para um movimento virtual. Melhor que o imaginário de muito videogame, e é uma pintura de ensinar a muito jovem neopop o que poderia ser uma vertente da pintura atual (2010:10).

Ainda que sua força formal possa depender de uma pressão/obsessão ordenadora para edificar o corpóreo, por certo que ela não resiste aos imperativos da imaginação. Alcides nos seduz porque a linguagem o faz vítima de uma sedução primeira. Conforme Leyla Perrone-Moisés (1990), um dos significados de seduzir é enganar com astúcia, desviar do caminho, influir sobre a imaginação. Portanto, guiado por esta necessidade cognitiva (ao modo Mignolo, aesthésica), que nada tem de simples, inocente ou inscrita em algo anterior, o suposto vivido, Alcides desenvolve, persiste e busca em suas composições plásticas extrair do rigor o delírio ${ }^{3}$. Onde mais poderiam habitar tais artefatos visuais, senão no mundo visionário de Alcides? Suas criações são, afinal, fabulações.

REFERÊNCIAS

CONCORRÊNCIA Fiat premia outro pintor mato-grossense. Revista Contato, Cuiabá, MT, ano X, n. 29, edição 1993, p.13.

DELEUZE, Gilles, GUATARI, Félix. O que é a Filosofia? Rio de Janeiro: Ed. 34, 1992 (Coleção TRANS). 
DUARTE, Paulo Sérgio. Arte brasileira: além do sistema. São Paulo: Galeria Brasiliana, 2010, p.10. Catálogo de Exposição.

GOLDSTEIN, Ilana. "Reflexões sobre a arte "primitiva: o caso do Musée Branly". Horizontes Antropológicos. Porto Alegre, ano 14, n. 29, jan/jun. 2008.

MACIEL, Maria Esther. A memória das coisas: ensaios de literatura, cinema e artes plásticas. Rio de Janeiro: Lamparina Editora, 2004.

MALDONADO-TORRES, Nelson. "A topologia do Ser e a geopolítica do conhecimento. Modernidade, império e colonialidade". Revista Crítica de Ciências Sociais. Coimbra: Centro de Estudos Sociais, n. 80, março 2008, pp: 71-114.

MIGNOLO, Walter. "Aiesthesis Decolonial". Calle 14. V. 4, no. 4. Enero-junio 2010, pp. 10-25.

MORENO, Pedro Paulo Gomes. "Un 'presente' y una invitación sin sobre de manila". Calle 14. V.4, no, 4. Enero-junio 2010, pp. 8-9.

PALERMO, Zulma. "Introducción: El arte latinoamericano en la encrucijada decolonial". Em PALERMO, Z. (Comp.) Arte e estética en la encrucijada descolonial. Buenos Aires: Del Signo, 2009, pp. 15-26.

PAREYSON, Luigi. Os problemas da estética. Trad. Maria Helena Nery Garcez. São Paulo: Martins Fontes, 2001.

PEREIRA, Marcelo Duprat. A expressão da natureza na obra de Paul Cézanne. Disponível em: <http:// www.marceloduprat.net/Textos/cezannelivro.pdf>. Acesso em: 15 out. 2010, p.47.

PERRONE-MOISÉS, Leyla. Flores da escrivaninha: ensaios. São Paulo: Companhia das Letras, 1990, p.7.

SANTOS, Boaventura de Souza; MENESES, Maria Paula (Orgs.). Epistemologias do Sul. Coimbra: Edições Almedina, 2009.

ULPIANO, Cláudio. A ideia de perfeição. Curso regular realizado na Escola Senador Correia. Aula transcrita de 19.12.1989, p.1. Disponível em: http://www.claudioulpiano.org.br. Acesso em: 03 de fev. 2009.

NOTAS

1. Texto desenvolvido no âmbito do projeto de pesquisa PNPD/CAPES "Artes visuais em Mato Grosso: acervo, difusão e crítica".

2. Sabemos que alguns especialistas estabelecem uma distinção entre "naïf" e "primitivo", no entanto abdicaremos de abordá-la aqui porque para os propósitos deste texto ela não nos parece importante. A antropóloga Ilana Goldestein (2008) cita, além da arte "naïf" e "primitiva", a ingênua, popular, bruta, a art art nègre, as que indicam a procedência como a africana, pré-colombiana, indígena, a das ilhas do Pacífico, entre outras.

3. Ao contrário do artista Arthur Bispo do Rosário, que no dizer argucioso da autora Maria Esther Maciel (2004: 24), vincular-se-ia a uma simetria do caos na qual "extrai do delírio o rigor". 